\title{
PENGARUH LATIHAN PLYOMETRIC TERHADAP HASIL TENDANGAN BOLA LAMBUNG JAUH PADA PEMAIN SEPAK BOLA
}

\author{
Oleh: Yusuf Sanggantara dan Fatkurahman Arjuna \\ Dosen Pendidikan Kesehatan Dan Rekresi - FIK UNY
}

\begin{abstract}
Abstrak
Penelitian ini dilatarbelakangi oleh ketika peneliti melakukan observasi serta pengambilan data di klub sepak bola Arkansas FC, power otot tungkai yang dimiliki para pemain klub sepak bola Arkansas FC Magelang masih sangat kurang maksimal sehingga pada saat melakukan tendangan lambung masih mengalami kesulitan.

Penelitian ini bertujuan untuk membuktikan pengaruh latihan plyometric terhadap peningkatan tendangan bola lambung jauh pemain sepak bola, membuktikan metode latihan yang lebih efektif dalam meningkatkan power otot tungkai. Jenis penelitian ini adalah eksperimental. Metode yang digunakan adalah metode tes, untuk mengetahui pengaruh latihan dan power tungkai terhadap jauhnya tendangan bola lambung. Untuk menganalisis data menggunakan uji beda mean, yaitu dengan membandingkan mean hasil pretest dengan Mean hasil posttest pada kelompok eksperimen. Populasi dalam penelitian ini adalah para pemain klub sepak bola Arkansas FC Magelang yang berumur 17-23 tahun dan masih aktif berlatih sepak bola, sampel sebanyak 24 pemain, yang semuanya terdiri atas laki-laki.

Hasil nilai rerata jauhnya tendangan saat pretest adalah sebesar 41,89 m sedangkan jauhnya rerata tendangan bola lambung saat posttest sebesar $44,57 \mathrm{~m}$. Ternyata besarnya rerata setelah diberikan metode latihan plyometric meningkat sebesar 2,68 $\mathrm{m}$ atau sebesar $6,39 \%$. Hal ini merupakan suatu hal yang sangat positif karena secara teknis kemampuan para pemain klub sepakbola Arkansas FC mengalami peningkatan yaitu pada aspek tendangan bola lambung.
\end{abstract}

Kata Kunci: plyometric, tendangan lambung

Di masa sekarang ini sepak bola telah mengalami perkembangan yang sangat pesat. Kemajuan olahraga sepak bola dari masa ke masa semakin mengalami peningkatan yang sangat signifikan dan berkembang dengan baik di berbagai penjuru dunia. Aris Setiawan menyatakan bahwa salah satu faktor yang sangat menentukan prestasi olahraga nasional adalah konsep latihan (training) itu sendiri. Sepak bola nasional (apalagi regional/lokal), yang disebut latihan Sepakbola lebih sering hanya bermain "bermain bola". Latihan sepak bola hanya dianggap sekedar berkumpul-kumpul saja, tendang bola sebentar langsung "bermain sepak bola" sebelas lawan sebelas dilapangan. Bisa dibayangkan, dalam satu kali "bermain Sepakbola” berapa kali rata-rata seseorang pemain menendang bola hanya 10-20 kali saja, dan dengan semakin berbakat seseorang, dia akan semakin menonjol, tetapi bagi yang "kurang berbakat" maka ia akan semakin tertinggal. Karena dilatih untuk "bermain sepak bola," teknik sepak bola pun tidak berkembang. 
Gerakan yang paling dominan dalam permainan sepak bola adalah menendang. Dengan gerakan menendang saja anak-anak sudah dapat bermain sepak bola. Tujuan menendang bola adalah untuk mengumpan (passing), menembak kegawang (shooting on the goal), dan menyapu (menjauhkan bola dari gawang sendiri) dan menyapu untuk menggagalkan serangan lawan (sweeping). Dalam sepak bola umpan atau passing tidak hanya dapat dilakukan dengan tendangan mendatar saja (menyusur tanah) namun juga dapat dilakukan dengan cara melambungkan bola ke arah sasaran atau rekan yang akan dituju. Tendangan lambung memiliki banyak kegunaan di antaranya adalah untuk memberikan umpan jauh ke daerah pertahanan lawan/sebagai umpan terobosan yang sulit dibaca lawan, untuk pemain bertahan (back) dapat menjauhkan bola langsung dari belakang ke daerah bertahan lawan sehingga bola dapat menjadi sebuah serangan balik, dan juga dapat digunakan untuk mencetak gol ke gawang lawan dari jarak yang cukup jauh apabila terkadang kiper lawan sedang tidak on position (maju beberapa meter meninggalkan gawang).

Dalam permainan sepak bola untuk bisa menghasilkan tendangan melambung jarak jauh lebih tepat apabila menggunakan teknik tendangan kura-kura kaki bagian dalam, karena akan menghasilkan tendangan bola yang parabola sehingga jarak yang akan ditempuh semakin jauh. Agar tendangan menjadi lambung dan keras tentu dibutuhkan power otot tungkai yang maksimal, oleh karena itu perlunya melatih power otot tungkai. Dalam melatih power otot tungkai, dapat digunakan salah satu metode latihan yaitu dengan metode plyometric. Materi latihan plyometric untuk meningkatkan daya ledak otot tungkai adalah latihan front jump dengan mistar sebagai rintangan yang dilewati. Menendang bola melambung agar menghasilkan tendangan yang jauh maka gerakan eksplosif otot tungkai sangat dibutuhkan untuk memperoleh gaya yang besar sehinga menghasilkan tendangan yang maksimal. Selain itu seorang pemain bola dituntut untuk memiliki power otot tungkai yang maksimal agar dapat menghindarkan diri dari cedera saat melakukan program latihan maupun saat bertanding.

Ketika melakukan pengamatan di lapangan, pemain-pemain asing (Eropa) bisa menendang bola sampai 2/3 lapangan dan juga memiliki kemampuan tendangan lambung dan akurasi yang bagus sehingga dapat memberikan kontribusi yang maksimal bagi sebuah tim sepak bola tersebut. Di sisi lain, kebanyakan pemain Indonesia masih kesulitan dalam mencapai titik tersebut. Selain itu, peneliti juga melakukan pengamatan dan pengambilan data jauhnya tendangan bola lambung terhadap para pemain sepak bola Arkansas FC Magelang. Para pemain masih kesulitan menggunakan tendangan lambung jauh untuk bermain dalam suatu pertandingan. Saat dilakukan pengambilan data rata-rata mereka hanya mampu menendang lambung kurang dari setengah lapangan saja. Atau hanya di kisaran jarak 41 meter. 
Hal ini tentu saja akan menyulitkan pemain di saat berlatih maupun bertanding. Padahal fungsi tendangan lambung sangat besar manfaatnya, di antaranya menjauhkan dari titik aman (dekat gawang), untuk mencetak gol (shooting), umpan lambung jarak jauh dan mengantisipasi ketika berada dalam kondisi hujan, dan ketika bertanding di lapangan yang tidak bagus.

Banyak metode latihan untuk meningkatkan power otot tungkai, misalnya dengan menggunakan skipping, barbell, dumbbell, dan juga bola berbeban (ball medicine). Dari sini peneliti ingin menggunakan metode baru yang lebih efektif dan efisien yang berkembang yaitu plyometric. Adapun latihan yang digunakan adalah front jump (meloncat melewati rintangan dengan dua kaki sebagai tumpuan). Apakah dengan latihan tersebut ada pengaruhnya terhadap tendangan lambung jarak jauh.

\section{KAJIAN PUSTAKA}

\section{Hakekat Sepak Bola}

Menurut Luxbacher (1998: 2) sepak bola dimainkan dua tim, masing-masing beranggotakan 11 orang. Masing-masing mempertahankan sebuah gawang dan mencoba menjebol gawang lawan.

Permainan sepak bola boleh dilakukan dengan seluruh bagian badan kecuali dengan kedua lengan (tangan). Hampir seluruh permainan sepak bola dilakukan dengan keterampilan kaki, kecuali penjaga gawang dalam memainkan bola bebas menggunakan anggota badannya, baik dengan kaki maupun tangan. Jenis permainan ini bertujuan untuk menguasai bola dan memasukkan bola ke dalam gawang lawan sebanyak mungkin dan berusaha mematahkan serangan lawan untuk melindungi atau menjaga gawangnya agar tidak kemasukan bola (Sukatamsi, 1997: 13).

Sepakbola adalah olahraga yang dilakukan dengan kaki untuk menendang, bola diperebutkan oleh dua kelompok yang masing-masing terdiri atas sebelas orang. Bermain sepak bola memerlukan teknik yang baik dan juga harus didukung oleh fisik dan mental yang kuat. Olahraga ini membutuhkan alat seperti sepatu bola untuk alat menendang dan juga bola sepak sebagai objek tendangan. Permainan sepak bola dilakukan di lapangan yang terbuka dan diberi gawang sebagai tempat untuk memasukkan bola dan menentukan pemenang. Sepak bola dalam permainanya dilakukan selama 2 x 45 menit.

Sepak bola merupakan kegiatan fisik yang cukup kaya struktur pergerakan. Dilihat dari taksonomi gerak secara umum, permainan sepak bola dapat secara lengkap diwakili oleh sebuah gerakan-gerakan dasar yang membangun pola gerak yang lengkap, mulai pola gerak lokomotor, nonlokomotor, sekaligus manipulatif. Keterampilan dasar ini dianggap sebagai 
keterampilan fundamental yang sangat berguna bagi pengembangan keterampilanketerampilan lain yang lebih kompleks.

\section{Hakikat Latihan}

Pengertian latihan menurut Bompa yang dikutip oleh Fatkurahman (2009: 14), Training is usually defined ass a systematic process of repetitive, progressive exercises, having the ultimate goal of improving athletic performance. Latihan bisa didefinisikan sebagai proses sistematis yang berubah, latihan yang berkelanjutan, serta memiliki tujuan yang maksimal dalam memperbaiki performa atlet.

Latihan merupakan aktivitas fisik dengan perencanaan, tersusun, dan dilakukan secara berulang-ulang bertujuan untuk mendapatkan perbaikan atau untuk memelihara kebugaran jasmani sesuai dengan tujuan yang diinginkan. Tujuan latihan yaitu untuk menentukan apa yang hendak dicapai. Pada umumnya tujuan latihan permulaan bersifat umum. Sebagai contoh tujuan latihan umum, para atlet harus mempunyai kondisi yang baik dari jantung, paru, otot, dan alat-alat lain dari tubuh. Tujuan latihan seharusnya dibuat bertingkat yaitu tingkat umum sampai akhirnya ke tingkat khusus untuk mencapai prestasi yang tertinggi.

Menurut Sukadiyanto (2009: 32) latihan merupakan proses pengakumulasian dari berbagai komponen kegiatan yang antara lain seperti durasi, jarak, frekuensi, jumlah ulangan, pembebanan, irama melakukan, intensitas, volume, pemberian waktu istirahat, dan densitas. Oleh karena itu dalam menyusun dan merencanakan proses latihan seorang pelatih harus mempertimbangkan faktor-faktor yang disebut komponen-komponen latihan tersebut.

\section{Hakikat Menendang Bola}

Seorang pemain sepak bola agar dapat bermain dengan baik dan benar dia harus bisa menendang dengan baik dan benar pula. Sucipto, dkk (2000:17) menjelaskan bahwa tendangan merupakan usaha untuk memindahkan bola. Menendang bola adalah salah satu karakteristik permainan sepak bola yang paling dominan. Tujuan menendang bola adalah untuk mengumpan (passing), menembak kegawang (shooting at the goal), dan menggagalkan serangan lawan (sweeping).

Menendang bola mempunyai dua arah putaran. Menurut Sukatamsi (1997: 33) arah putaran jalannya bola ada dua macam, yaitu:

a. Tendangan lurus (langsung). Bola setelah ditendang tidak berputar sehingga bola melambung lurus dan jalannya kencang. Pada tendangan lurus ini, tenaga tendangan melalui titik pusat bola, keluar menuju lintasan bola (lurus).

b. Tendangan melengkung (slice). Bola setelah ditendang berputar ke arah yang berlawanan dengan arah tendangan dan arah bola, apabila bola melambung setelah sampai puncak akan 
turun vertikal. Pada tendangan melengkung ini tenaga tendangan tidak melalui pada titik pusat bola, tenaga tendangan menyinggung bola dan memutar bola sehingga lintasan bola melengkung atau berupa garis lengkung sesuai dengan arah putaran bola.

\section{Tendangan Bola Lambung dalam Sepak Bola}

Agar dapat menendang bola melambung dengan hasil yang jauh di samping dibutuhkan power otot tungkai juga diperlukan penguasaan teknik menendang bola yang baik. Perlu diperhatikan pula bahwa teknik-teknik tertentu dapat memberikan hasil yang diharapkan sedangkan untuk menghasilkan suatu tendangan yang melambung dan jarak yang jauh lebih tepat jika digunakan kura-kura kaki bagian dalam (inside of the instep). Analisis gerak menendang dengan menggunakan punggung kaki bagian dalam sebagai berikut:

a. Posisi badan berada di belakang bola, sedikit serong kurang lebih 40 derajat dari garis lurus bola, kaki tumpu diletakkan di samping belakang bola kira - kira $30 \mathrm{~cm}$ dengan ujung kaki membuat sudut 40 derajat dengan garis lurus bola.

b. Kaki tendang berada di belakang bola dengan ujung kaki serong kurang lebih 40 derajat ke arah luar. Kaki tendang tarik ke belakang bola dan ayunkan ke depan sehingga mengenai bola. Perkenaan kaki dengan bola tepat di punggung kaki bagian dalam dan tepat pada tengah bawah bola dan pada saat kaki mengenai bola pergelangan kaki dikunci.

c. Gerak kaki lanjutan kaki tendang diangkat dan diarahkan ke depan.

d. Pandangan mengikuti jalannya bola ke sasaran.

e. Lengan dibuka berada di samping badan sebagai keseimbangan (Sucipto, dkk, 2000: 21).

\section{Hakikat Power Otot Tungkai pada Tendangan Lambung}

Power diartikan sebagai kekuatan dan frekuensi atau kekuatan yang terbagi dengan waktu, maka beban lebih resistif dan temporal harus diberikan. Pada latihan-latihan peningkatan power (plyometric), beban lebih resistifnya berupa perubahan arah yang cepat pada suatu anggota tubuh atau seluruh tubuh, seperti mengatasi gaya akibat terjatuh, naik anak tangga, terpental, meloncat, melangkah lebar atau melompat. Beban lebih temporal dapat dilakukan dengan berkonsentrasi pada pelaksanaan gerakan secepat dan seintensif mungkin.

Daya otot adalah sama dengan kekuatan explosive power dari otot bergantung pada dua faktor yang saling berkaitan. Jadi, power $=$ kekuatan $\mathrm{x}$ kecepatan $=$ kekuatan $\mathrm{x}$ jarak. Melatih power harus memiliki kekuatan dan kecepatan terlebih dahulu, karena apabila komponen biomotorik tersebut tidak dipenuhi akan mempermudah terkena cedera dalam melatih power. Wujud gerak power adalah explosive, oleh karena itu bentuk latihan kekuatan dapat menjadi bentuk latihan power namun bebannya harus ringan dan dilakukan dengan irama cepat 
(explosive). Selain itu untuk meningkatkan power juga bisa digunakan metode yang popular dalam berbagai cabang olahraga yaitu metode latihan plyometrics.

\section{Latihan Plyometrics}

Menurut Bompa yang dikutip oleh Fatkurahman Arjuna (2009: 28 ) The action involved in a plyometrics type of exercise relies mechanically on the stretch reflex wich is found in the belly of the individual muscle. Dapat disimpulkan bahwa latihan plyometrics adalah latihan yang menggunakan berat badan sendiri sebagai beban dan yang dilakukan dengan lompatloncat. Menurut Bompa yang dikutip Fatkurahman Arjuna (2009: 28) secara umum latihan plyometrics dapat dibedakan dalam dua kategori yaitu: (1) low impact exercises adalah usaha tunggal yang sungguh-sungguh dengan intensitas rendah, contohnya skipping, rope jump: low and short steap, (2) high impact exercises adalah latihan plyometrics yang lebih menekankan pada stamina dan kecepatan keseluruhan dengan melibatkan beberapa usaha secara berturutturut dengan intensitas tinggi, contohnya standing long, triple jump, jump: higher and longer steps, hops and jump, heavy medicine ball.

Bentuk gerakan dasar plyometric yang digunakan dalam penelitian ini adalah front cone hops (Fatkurahman Arjuna, 2009: 34) (Gambar 4).
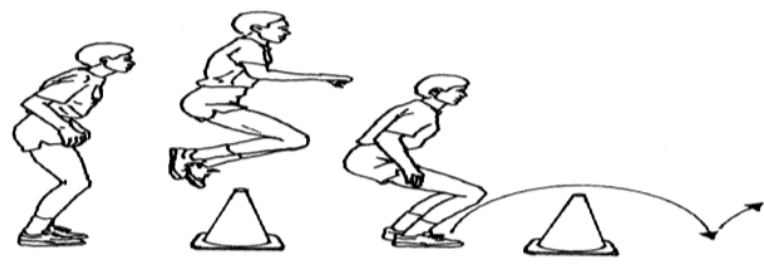

Gambar 4. Front Cone Hops

Equipment:

A row of 6 to 10 cones or small barriers ( 8 to 12 inches tall) set up approximately three to six feet apart

Tabel 2. Program Latihan Plyometric

\begin{tabular}{|c|c|c|}
\hline \multirow{2}{*}{$\begin{array}{l}\text { Lama Latihan } \\
\text { Intensitas }\end{array}$} & \multicolumn{2}{|c|}{1 Minggu (Senin, Rabu, Jumat) } \\
\hline & \multicolumn{2}{|c|}{ Sedang } \\
\hline Waktu (durasi) & \multicolumn{2}{|l|}{$30-60$ menit } \\
\hline Program Latihan & \multicolumn{2}{|c|}{ Plyometric (front cone hops) } \\
\hline JENIS LATIHAN & TAKARAN LATIHAN & KETERANGAN \\
\hline $\begin{array}{l}\text { Latihan Utama: } \\
\text { Plyometric } \\
\text { (Front Cone Hops) }\end{array}$ & $\begin{array}{l}\text { Frekuensi: } 3 \text { kali/minggu } \\
\text { Durasi: } 30-60 \text { menit } \\
\text { Repetisi: } 4-10 \mathrm{kali} \\
\text { Set: } 3-5 \text { set } \\
\text { Irama: Lancar } \\
\text { Recovery: } 10-15 \text { detik antar sesi \& } \\
\quad 120 \text { detik/set. }\end{array}$ & $\begin{array}{l}\text { Melakukan } \\
\text { peningkatan repetisi } \\
\text { dan set secara } \\
\text { bertahap setiap } \\
\text { minggunya. }\end{array}$ \\
\hline
\end{tabular}

Sumber: Fatkurahman Arjuna (2009: 91) 


\section{Tinjauan Secara Anatomi Latihan Plyometric}

Gerakan latihan front jump ini perlu dianalisis guna mendukung hipotesis secara anatomi. Secara anatomi gerakan front jump melibatkan otot tungkai bagian atas dan otot tungkai bagian bawah sehingga semua otot yang ada dibagian tersebut bekerja menerima beban latihan. Latihan ini sama-sama melatih kekuatan dan kecepatan otot tungkai atau yang sering disebut power otot tungkai.

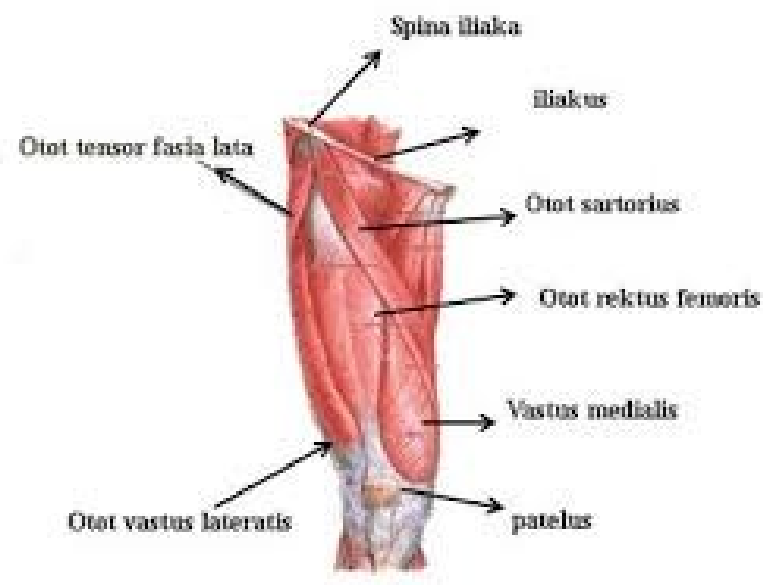

Gambar 5. Perkenaan Otot Paha saat Menendang Bola Lambung Sumber: Diktat Anatomi (2011: 88)

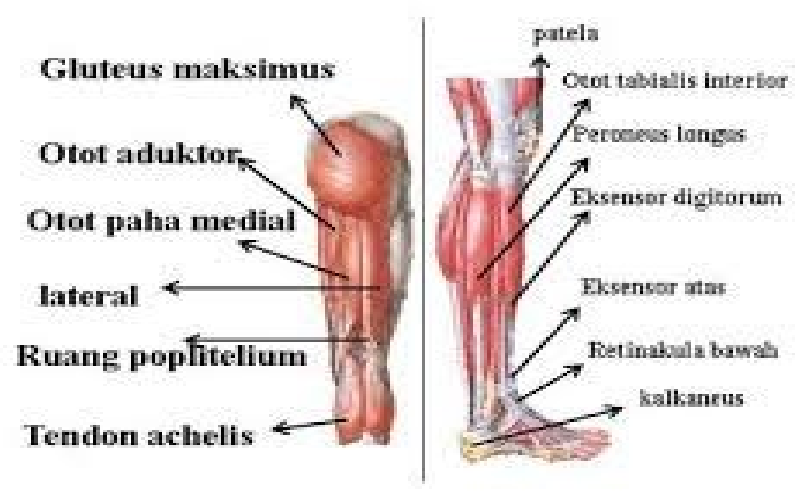

Gambar 6. Perkenaan Otot Tungkai saat Menendang Bola Lambung Sumber: Diktat Anatomi (2011: 90)

Gerakan fleksi paha (gerakan menekuk paha), otot-otot yang berperan adalah otot sartorius, illiacus, dan gracialis. Gerakan ekstensi paha (gerakan meluruskan paha), otot-otot yang terlibat yaitu bisep femoris, semitedinosus (kelompok harmstring) dan juga gluteus maksimus, dan minimus. Gerakan fleksi lutut dan kaki (gerakan menekuk lutut dan kaki), otototot yang berperan yaitu gastronemius. Gerakan ekstensi lutut yaitu suatu gerakan latihan kaki untuk meluruskan kedua lutut bersamaan, otot - otot yang berperan yaitu otot rectus femoris, vastus lateralis, vastus medialis, dan intermedialis (kelompok quadriceps). 


\section{Klub Sepak Bola Arkansas FC Magelang}

Klub sepak Bola Arkansas FC berdiri pada tahun 1998 dan beranggotakan lebih dari 40 orang baik di tim senior maupun junior. Klub sepak Bola ini merupakan klub sepak Bola prestasi tidak hanya klub sepak Bola rekreasi saja. Klub ini merupakan salah satu peserta dari kompetisi divisi 3 PSSI wilayah Kabupaten Magelang. Klub sepak Bola ini terdiri atas tingkat sekolah menengah pertama sampai dengan tingkat mahasiswa yang berkuliah, sudah lulus kuliah, dan bahkan sudah ada pula yang bekerja. Klub sepak bola Arkansas FC melakukan program latihan berlokasi di lapangan sepak bola Kecamatan Salaman, Magelang setiap hari Rabu, Jumat, dan Minggu. Klub sepak bola ini memiliki tiga pelatih, yaitu Muhamad Kadik, Suprapto, dan Mirza Rosi Nazari.

\section{METODE PENELITIAN}

Penelitian ini termasuk penelitian eksperimen. Penelitian ini bertujuan untuk mengetahui pengaruh latihan plyometric terhadap hasil jauhnya tendangan lambung para pemain sepak bola Arkansas FC Magelang. Penelitian ini menggunakan preeksperimental, desain yang digunakan dalam penelitian ini adalah One Group Pretest-Posttest Design (Sugiyono, 2015: 75). Dalam desain ini observasi dilakukan sebanyak dua kali yaitu, sebelum eksperimen dan sesudah eksperimen. Penelitian ini dilaksanakan selama 6 minggu dan dimulai pada bulan Februari sampai bulan April 2016. Populasi yang digunakan dalam penelitian ini adalah para pemain sepak bola klub Arkansas FC Magelang.

Keseluruhan populasi dalam penelitian ini memiliki beberapa kesamaan kriteria, yaitu Bermain di klub sepak bola yang sama, memiliki rentang usia yang relatif sama antara 17-23 tahun, Sudah berlatih bersama lebih dari tiga bulan secara rutin, bersedia menjadi subjek penelitian. Adapun subjek penelitian yang digunakan dalam penelitian ini adalah para pemain klub sepak bola Arkansas FC Magelang sebanyak 24 Orang.

\section{HASIL PENELITIAN}

\section{Data Tes Tendangan Bola Lambung Jauh}

Tes awal yang dilakukan ialah menendang bola sejauh mungkin dengan menggunakan kaki yang dominan untuk mengetahui kemampuan kekuatan (power) tungkai pemain sepak bola Arkansas FC. Cara melakukan tendangan bola lambung jauh yaitu pemain melakukan tendangan sebanyak tiga kali kemudian diukur tendangan terjauh dengan menggunakan alat ukur yaitu meteran. Setelah itu data yang diperoleh diambil dari data tendangan terjauh yang dilakukan oleh pemain tersebut. 
Data yang dimaksud bisa dilihat pada Tabel 3 dan Tabel 4 tentang hasil jauhnya tendangan bola lambung pemain sepak bola Arkansas FC.

Tabel 1. Hasil Pretest dan Posttes Tendangan Bola Lambung Jauh Pemain Sepak Bola Klub Arkansas FC Magelang

\begin{tabular}{|c|c|c|}
\hline No & Hasil Jauhnya Tendangan Pretest & Hasil Jauhnya Tendangan Posttest \\
\hline 1. & $43,3 \mathrm{~m}$ & $45,5 \mathrm{~m}$ \\
\hline 2. & $42,1 \mathrm{~m}$ & $43,7 \mathrm{~m}$ \\
\hline 3. & $43,4 \mathrm{~m}$ & $46,2 \mathrm{~m}$ \\
\hline 4. & $40,6 \mathrm{~m}$ & $42,1 \mathrm{~m}$ \\
\hline 5. & $40,6 \mathrm{~m}$ & $43,4 \mathrm{~m}$ \\
\hline 6. & $40,2 \mathrm{~m}$ & $42,2 \mathrm{~m}$ \\
\hline 7. & $39,4 \mathrm{~m}$ & $41,8 \mathrm{~m}$ \\
\hline 8. & $40,1 \mathrm{~m}$ & $43,2 \mathrm{~m}$ \\
\hline 9. & $43,6 \mathrm{~m}$ & $46,2 \mathrm{~m}$ \\
\hline 10. & $43,5 \mathrm{~m}$ & $46,4 \mathrm{~m}$ \\
\hline 11. & $44,6 \mathrm{~m}$ & $47,6 \mathrm{~m}$ \\
\hline 12. & $41,4 \mathrm{~m}$ & $43,3 \mathrm{~m}$ \\
\hline 13. & $39,7 \mathrm{~m}$ & $42,1 \mathrm{~m}$ \\
\hline 14. & $42,3 \mathrm{~m}$ & $45,8 \mathrm{~m}$ \\
\hline 15. & $43,2 \mathrm{~m}$ & $47,1 \mathrm{~m}$ \\
\hline 16. & $39,2 \mathrm{~m}$ & $42,9 \mathrm{~m}$ \\
\hline 17. & $40,3 \mathrm{~m}$ & $43,2 \mathrm{~m}$ \\
\hline 18. & $46,3 \mathrm{~m}$ & $48,8 \mathrm{~m}$ \\
\hline 19. & $42,4 \mathrm{~m}$ & $45,3 \mathrm{~m}$ \\
\hline 20. & $40,5 \mathrm{~m}$ & $43,7 \mathrm{~m}$ \\
\hline 21. & $40,2 \mathrm{~m}$ & $42,3 \mathrm{~m}$ \\
\hline 22. & $44,1 \mathrm{~m}$ & $47,1 \mathrm{~m}$ \\
\hline 23. & $42,7 \mathrm{~m}$ & $45,8 \mathrm{~m}$ \\
\hline 24. & $41,8 \mathrm{~m}$ & $44,2 \mathrm{~m}$ \\
\hline
\end{tabular}

$M$ posttest $>M$ pretest, terdapat pengaruh latihan plyometric terhadap hasil jauhnya tendangan bola lambung jauh pada pemain sepak bola Arkansas FC Magelang. Rangkuman Hasil perbandingan mean 
Tabel 2. Hasil Perbandingan Mean

\begin{tabular}{|c|c|c|c|}
\hline Kelompok & Mean & $\begin{array}{c}\text { Mean } \\
\text { Different }\end{array}$ & Persentase \\
\cline { 1 - 2 } Jauhnya tendangan pretest & 41,89 & \multirow{2}{*}{2,68} & $\mathbf{6 , 3 9 \%}$ \\
\cline { 1 - 2 } Jauhnya tendangan posttest & 44,57 & & \\
\cline { 1 - 2 }
\end{tabular}

Berdasarkan tabel di atas diperoleh rerata pretest sebesar 41,89 dan rerata posttest sebesar 44,57. Peningkatan rerata dari pretest ke posttest adalah sebesar 2,68 atau jika dipersentasekan peningkatan atau pengaruh pemberian metode latihan plyometric terhadap tendangan bola lambung jauh pada klub sepak bola Arkansas FC sebesar 6,39\%.

\section{PEMBAHASAN}

Pengujian beda mean, diperoleh hasil $M$ posttest $>M$ pretest, dan menunjukkan bahwa terdapat pengaruh pemberian metode latihan plyometric terhadap jauhnya tendangan bola lambung para pemain klub sepak bola Arkansas FC Magelang. Nilai rerata jauhnya tendangan saat pretest adalah sebesar 41,89 sedangkan jauhnya rerata tendangan bola lambung saat posttest sebesar 44,57 . Ternyata besarnya rerata setelah diberikan metode latihan plyometric meningkat sebesar 2,68 atau sebesar 6,39\%.

Latihan plyometric adalah bentuk latihan expolisve power dengan menggunakan kontraksi otot yang sangat cepat dan kuat dalam mengatasi tahanan, yakni otot selalu berkontraksi baik saat memanjang maupun saat memendek dalam waktu yang cepat. Dengan melakukan latihan plyometric diharapkan dapat meningkatkan kemampuan para pemain sepak bola klub Arkansas FC, khususnya jauhnya tendangan lambung karena pada latihan ini otot-otot yang mendukung sudah dibiasakan dengan latihan yang benar dan perkenaan otot tersebut telah dimaksimalkan. Harapan ini telah dibuktikan dengan hasil penelitian bahwa jauhnya tendangan lambung pemain klub sepak bola Arkansas FC Magelang telah mengalami peningkatan sebesar 6,39 \% dari hasil sebelumnya.

\section{KESIMPULAN}

Berdasarkan hasil penelitian yang telah dibahas pada bab sebelumnya tentang pengaruh latihan plyometric terhadap peningkatan jauhnya tendangan bola lambung pemain sepakbola klub Arkansas FC, dapat diambil kesimpulan pemberian latihan plyometric berpengaruh terhadap peningkatan jauhnya tendangan bola lambung pemain sepak bola klub Arkansas FC Magelang sebesar 6,39\%. 


\section{DAFTAR PUSTAKA}

Abdul Mafudin Alim. (2007). Pengaruh Latihan Plyometrics dan Weight Training terhadap Tinggi Loncatan pada Atlet Bola Voli PAB Yogyakarta. Skripsi. Fakultas Ilmu Keolahragaan. Universitas Negeri Yogyakarta.

Dhanik Fahrizal. (2007). Pengaruh Latihan Plyometrics Dengan Tumpuan Dua Kaki Secara Bersama-sama dan Bergantian Terhadap Peningkatan Power Otot Tungkai Atlet Taekwondo di Bantul. Skripsi. Fakultas Ilmu Keolahragaan. Universitas Negeri Yogyakarta

Fatkurahman Arjuna. (2009). Pengaruh Model Latihan Fisik dan Power Tungkai terhadap Kecepatan Tendangan Atlet Karate. Tesis. Program Pascasarjana. Universitas Negeri Yogyakarta.

Luxbacher. (1998). Sepak Bola. Jakarta: PT. Raja Grafindo Persada.

M. Barrow. (1971). Physical Education. Philadelphia.

M. Sajoto. (2002). Peningkatan dan Pembinaan Kekuatan Kondisi Fisik dalam Olahraga.

Sucipto, dkk. (2000). Sepak Bola. Jakarta: Departemen Pendidikan Nasional.

Sukadiyanto. (2009). Pengantar Teori dan Metodologi Melatih Fisik. Yoyakarta: Fakultas Ilmu Keolahragaan. Universitas Negeri Yogyakarta.

Sukatamsi. (1997). Permainan Besar I Sepak Bola. Jakarta : Universitas Terbuka.

UNY. (2011). Pedoman Tugas Akhir: Yogyakarta. 